\title{
Effect of Neuromuscular Exercises on Osteoarthritic Knee Functional Mobility after Hyaluronic Acid Injection
}

\author{
AHMED M.M. ABD EL-AZIZ, M.Sc.*; ALAA EL-DIN A. BALBA, Ph.D.**; \\ MAHA M. MOHAMMED, Ph.D.** and MOHIE EL-DIN M. FADEL, M.D.*** \\ The Department of Musculoskeletal Disorders \& their Surgery, Faculty of Physical Therapy, \\ Pharos* and Cairo** Universities and the Department of Orthopedic Surgery, Faculty of Medicine, \\ Alexandria University***, Egypt
}

\begin{abstract}
Background: Knee Osteoarthritis (OA) is most common disabling disease with middle and old ages widely distributed need future researches to detect the effect of therapy. Recently Hyaluronic Acid (HA) and therapeutic exercises like neuromuscular exercises used as treatment option with recent good evidence.
\end{abstract}

Purpose: To detect the effect of neuromuscular exercises on knee OA after Intra-Articular Hyaluronic Acid (IA-HA) injections in the functional mobility.

Patients and Methods: This study was conducted on thirty patients both gender with mild to moderate knee OA. Their age ranged from 40-60 years old. All patients were referred by orthopedic surgeons who are responsible for diagnosis and injecting HA based on clinical and radiological examination. All patients were randomly assigned into 2 groups: Group (A) this group included 15 patients received IA-HA injections, Group (B) This group included 15 patients received IA-HA injections and neuromuscular exercises, three sessions per week for one month. The study was conducted at private physical therapy orthopedics rehabilitation center from October 2016 to July 2017.

Evaluation: Timed Up and Go (TUG) test was used to assess the functional performance. Results showed that both groups were effective in improving of the functional mobility, but HA alone (Group A) were less effective than HA added to neuromuscular exercises.

Conclusion: It can be concluded that both HA injection and $\mathrm{HA}$ added to neuromuscular exercises are effective treatment for knee OA functional mobility, and adding neuromuscular exercises gained better results than isolated.

Key Words: Knee osteoarthritis - Hyaluronic acid - Neuromuscular exercises - TUG test.

Correspondence to: Dr. Ahmed M.M. Abd El-Aziz, The Department of Musculoskeletal Disorders \& their Surgery, Faculty of Physical Therapy, Pharos University, Egypt

\section{Introduction}

OSTEOARTHRITIS is a disabling disease that leads to severe morbidity and deterioration of physical activity [1]. It is the most common joint problem and is one of the main causes of disability in the elderly [2].

The increased prevalence of OA and the medical costs associated with Total Knee Replacement (TKR) surgery for terminal stage OA motivate a search for agents that can decelerate OA progression [3].

The intra-articular injections of HA has been documented as a treatment of choice since the 1990s [4,5]. There is a recent strong evidence for the efficacy of IA-HA in decreasing pain and increasing function in knee OA [6]

On the other hand the patients with degenerative knee disease as OA have sensorimotor affection in terms of sensory dysfunction, decreased functional activity [7], lower limb muscle weakness and altered muscle activation patterns [8]. These sensorimotor changes are reported not only for the affected lower limb compared with the unaffected side but also compared with a reference group from the population [9]

There is no uniform definition of neuromuscular exercise, other terms such as functional exercise and proprioceptive, agility, or perturbation training are used in the literature. Neuromuscular exercises for the lower limb typically involve multiple joints and muscle groups performed in functional weightbearing positions. Emphasis is on the quality and efficiency of movement, as well as alignment of the trunk and lower limb joints [10]. Neuromuscular 
exercises also considered to be beneficial in decreasing pain and improvements in self-reported outcomes, sensorimotor function, and functional stability with osteoarthritic knee [10].

\section{Subjects and Methods}

The study design is randomized controlled trial which was conducted at private Physical Therapy Orthopedics Rehabilitation Center from October 2016 to July 2017. It was conducted on thirty patients (males and females) with mild to moderate knee OA, their age ranged from 40-60 years; the participants were selected from a private orthopedic and arthroscopic center in Alexandria. Patients were enrolled to the study and signed in a consent form; all had knee OA from mild to moderate degree. patients were excluded if they had ages more than 60 years or less than 40 years, patients with no radiographic evidence of knee OA or with severe OA (grade IV according to $\mathrm{K} / \mathrm{L}$ classification), patient with bilateral knee OA, congenital or acquired inflammatory or neurological (systemic or local) diseases involving the knee, repeated treatment with steroids, patients who had received either an oral, topical or suppository pharmacological treatment within two weeks before the study, patients who had secondary knee OA, patients with rheumatoid arthritis, patients who had received joint replacement surgery in either Knee and/or a hip, patients who had allergies to either HA or psychiatric disorders.

They were divided randomly into two equal Groups (A, B), closed envelop method was used. Group A included 15 patients who received IAHA injections. Group B included 15 patients who received IA-HA injections and neuromuscular exercise.

\section{Assessment procedures:}

Functional performance was assessed using TUG test. Participant was asked to stand up, walk to a mark $3 \mathrm{~m}$ away, turn around and return to sit back in the chair at their regular pace. Regular walking aid was allowed and recorded. Same chair is needed for re-testing.

\section{Treatment procedures:}

Group A (control group): Patients were assigned to the Group A (HA group) took three intra-articular injections (one injection every one week) of high molecular weight HA (Orthovisc $2 \mathrm{ml} ; 15 \mathrm{mg} / \mathrm{ml}$; Anika Therapeutics Inc., Bedford, MA), [11], all devices were supplied as sterile, pre-filled syringes containing clear colorless solution, injection were given by a physician experienced in the procedure using a 21-gaugeneedle under aseptic conditions. Every patient was asked to report any side effects, allergic reactions or unusual painful site after needle entrance, patient asked not to use any kind of analgesics or exert unusual efforts.

Group B (study group): Patients was assigned to Group B (neuromuscular exercises +HA) who received a previous injection with same technique in addition to programme of neuromuscular exercises for a total of 12 treatment sessions in a month (three sessions per week) duration.

\section{Neuromuscular exercises: (Appendix):}

Progression through the levels within a certain exercise was an important component of the program. As a guide, participants were progressed at a level when they have accommodated to it and the level was not aggravating their pain. The neuromuscular exercises were applied to the patient with progression according to pain response and patient tolerance. All exercises were progressively increased for each patient according to his/her individual capability variation as the external support, repetitions, and velocity of the movements.

A modified form of neuromuscular protocol which designed by Bennel et al., [12] for knee OA has been used, aiming to be suitable to Egyptian patients with knee OA with age range 40-60 years.

Participants in the neuromuscular exercise group were aware of the following points:

- Quality of performance was critical and the participant must attempt to position their knee over the foot throughout the movements.

- Knee flexion didn't exceed $30^{\circ}$ during the exercises (except when performing the chair stand exercise). This was to minimize the risk of increasing knee pain and was relevant to the range of knee flexion during walking, our primary outcome.

- Although some discomfort was expected, the exercises should be performed within tolerable levels of pain. Pain subsided to usual levels by the next day with no increase in swelling following the exercise session. Participants were assisted in determining whether pain levels during and for a short time after the exercises were acceptable by using a numeric pain rating scale [13]. Where zero is (no pain) and ten is (pain as bad as it could be). Pain up to two on the scale is considered (safe), pain up to a level of five is considered acceptable (as long as temporary), and pain above five is considered (high risk) [14] 
- Safety was ensured by using hand support or having hand support within easy reach. This was used for balance support and for maintaining quality of performance throughout the movements.

\section{Statistical analysis:}

Data were analyzed by the SPSS statistical package (Version 20.0). Descriptive statistics were calculated for TUG in the form of mean \pm standard deviation.

Before treatment, homogeneity between groups was tested by Chi square test for patients' age and body mass, height, and BMI values.

After treatment, within and between groups differences in both groups (IA-HA and IA-HA+ neuromuscular exercises), were tested by multipairwise comparison test (post hoc test) for TUG test. Significance level was set at $p<0.05$.

\section{Results}

\section{General characteristics:}

The current study was conducted on 30 patients (17 females and 13 males) suffering from mild to moderate degree knee OA. They were assigned randomly into two equal studies groups. As indicated by the independent $t$-test, there were no significant differences $(p>0.05)$ in the mean values of age, body mass, and height between both tested groups (Table 1). Chi square revealed there was no significant differences between both groups in sex distribution $(p>0.05)$.

\section{$2 X 2$ mixed design MANOVA: \\ 1- Overall effect:}

Statistical analysis using 2 X 2 mixed design MANOVA indicated that there were significant effects of the tested group (the first independent variable) on the tested dependent variable; time up and go test. In addition, there were significant effects of the measuring periods (the second independent variable) on the tested dependent variable. As well as, the interaction between the two independent variables was significant, which indicates that the effect of the tested group (first independent variable) on the dependent variable was influenced by the measuring periods (second independent variable) ${ }^{\left(p=0.000 P^{*}\right)}$ (Table 2$)$.

\section{2- Multiple pairwise comparison tests (post hoc tests) for time up and go test: \\ 1- Within groups:}

As presented in (Table 3) and illustrated in Fig. (1), within group's comparison the mean \pm SD values of time up and go test in the "pre" and "post" tests. Multiple pairwise comparison tests (post hoc tests) revealed that there was significant reduction of time up and go test at post-treatment in compare to pre-treatment $(p$-value $=0.0001 *)$. While, the mean \pm SD values of time up and go test in the "pre" and "post" tests revealed that there was significant reduction of time up and go test at posttreatment in compare to pre-treatment ( $p$-value $=0.0001 *)$.

\section{2- Between groups:}

Considering the effect of the tested group (first independent variable) on time up and go test, multiple pairwise comparison tests (post hoc tests) revealed that the mean values of the "pre" test between both groups showed no significant differences with ( $p=0.899)$. As well as, multiple pairwise comparison tests (post hoc tests) revealed that there was significant difference of the mean values of the "post" test between both groups with $\left(p=0.017^{*}\right)$ and this significant reduction in favor to Group B.

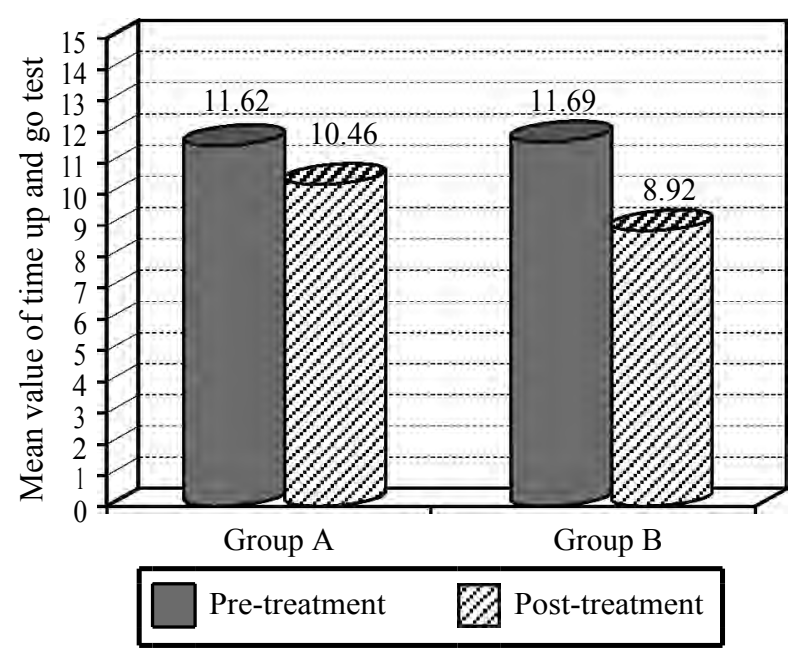

Fig. (1): Mean values of time up and go test pre and post tests in both groups.

Table (1): Physical characteristics of patients in both Groups (A \& B).

\begin{tabular}{|c|c|c|c|}
\hline Items & $\begin{array}{c}\text { Group A } \\
\text { Mean } \pm \text { SD }\end{array}$ & $\begin{array}{c}\text { Group B } \\
\text { Mean } \pm \text { SD }\end{array}$ & $\begin{array}{c}\text { Comparison } \\
p \text {-value }\end{array}$ \\
\hline Age (years) & $47 \pm 5.04$ & $47.66 \pm 4.8$ & 0.714 \\
\hline Body mass (Kg) & $79.93 \pm 8.45$ & $76.86 \pm 9.03$ & 0.345 \\
\hline Height (cm) & $173.06 \pm 6.90$ & $170.33 \pm 7.29$ & 0.301 \\
\hline $\mathrm{BMI}\left(\mathrm{kg} / \mathrm{m}^{2}\right)$ & $26.20 \pm 1.55$ & $26.12 \pm 1.70$ & 0.903 \\
\hline $\begin{array}{l}\text { Sex distribution } \\
N(\%)\end{array}$ & Group A & Group B & $p$-value \\
\hline Female & $8(53.3 \%)$ & $9(60 \%)$ & 0.713 \\
\hline Male & $7(46.7 \%)$ & $6(40 \%)$ & \\
\hline $\begin{aligned} * \mathrm{SD} & : \text { Standard D } \\
p & : \text { Probability }\end{aligned}$ & $\begin{array}{l}\text { S : } \\
\text { NS : }\end{array}$ & $\begin{array}{l}\text { ignificance. } \\
\text { on-Significar }\end{array}$ & \\
\hline
\end{tabular}


Table (2): The 2 X 2 mixed design Multivariate Analysis of Variance (MANOVA) for all dependent variables at different measuring periods between both groups.

\begin{tabular}{ll}
\hline Source of variation & $p$-value \\
\hline Groups & $0.006^{*}$ \\
Measuring periods & $0.0001^{*}$ \\
Interaction & $0.0001^{*}$ \\
\hline
\end{tabular}

*: Significant at alpha level $<0.05$.

Table (3): Mean \pm SD and $p$-values of time up and go test pre and post test at both groups.

\begin{tabular}{lcllll}
\hline $\begin{array}{l}\text { Time up } \\
\text { and go test Mean } \pm \text { SD Mean } \pm \text { SD change }\end{array}$ & $\begin{array}{c}\text { Pre test } \\
\text { and }\end{array}$ & $\begin{array}{c}\text { Post test } \\
\text { Mo of }\end{array}$ & $\begin{array}{c}p \text { - } \\
\text { value }\end{array}$ \\
\hline Group A & $11.62 \pm 1.53$ & $10.46 \pm 1.72$ & 1.16 & $9.98 \downarrow$ & $0.0001^{*}$ \\
Group B & $11.69 \pm 1.59$ & $8.92 \pm 1.58$ & 2.76 & $23.6 \downarrow$ & $0.0001^{*}$ \\
MD & -0.07 & 1.53 & & & \\
$p$-value & 0.899 & $0.017^{*}$ & & & \\
\hline
\end{tabular}

*: Significant level is set at alpha level $<0.05$.

SD: Standard Deviation.

MD: Mean Difference.

$p$-value: Probability value.

\section{Discussion}

Knee OA is a one of the most common disturbing disease associated with pain, stiffness and limited Activity of Daily Living (ADL). Safe with less side effect treatment, like HA injections and physical therapy exercises highly needed. There is a growing evidence of specific therapy like neuromuscular exercises which aims to improve common knee OA symptoms.

Up to authors' knowledge there were no previous literature discussed the effect of HA injection on functional mobility as a form of TUG test with a case of knee OA.

The current study showed a significant $(p<0.05)$ improvement in functional mobility of knee OA when evaluated by TUG test. These results confirmed the effective role of HA injection added to neuromuscular exercise in functional mobility improvement.

There is no uniform definition of neuromuscular exercise, other terms such as balance, functional exercise and proprioceptive, agility, or perturbation training are used in the literature [10]. Diracoglu et al., claimed that the neuromuscular training at the form of balance exercise for knee OA patients induces a significant effect on functional mobility when tested by (10 stairs climbing, and 10-m walking times) [15], as neuromuscular exercise increases mechanoreceptor sensitivity (muscle spindle sensitivity in particular) [16] . Also, by increasing muscle mass, exercise therapy might be able to increase the number of muscle spindle units, both might be the case of functional mobility improvement [17]

Elgendy et al., reported that neuromuscular exercises produced significant improvement on functional mobility with knee OA patients [18], neuromuscular exercises provide intra-articular pressure which achieved through Closed Kinetic Chain position (CKC), that pressure stimulates mechanoreceptor and stresses the knee similar to stresses in ADL, so it might be the cause of functional mobility improvement.

Khalaj et al., concluded a clinical trial on sixty subjects with knee OA neuromuscular exercises were introduced to the patients in the form of balance training. They used TUG test to evaluate dynamic balance and functional mobility. They found significant improvement in TUG after balance training. Results came into agreement with our findings [19], even they didn't use IA-HA injections added to the neuromuscular exercises, they found significant improvement on functional mobility, so we suggest the adding of both beneficial treatments in our study is the cause of higher improvement than HA alone.

\section{Conclusion:}

Injection of HA is a successful treatment for improvement of physical mobility of knee OA.

- Adding neuromuscular exercises to HA injections have a better effect on improving physical mobility than HA injection alone.

\section{References}

1- TROJIAN T.H., CONCOFF A.L., JOY S.M., HATZENBUEHLER J.R., SAULSBERRY W.J. and COLEMAN C.I.: AMSSM scientific statement concerning viscosupplementation injections for knee osteoarthritis: Importance for individual patient outcomes. British Journal of Sports Medicine, 50 (2): 84-92, 2016.

2- BRUYERE O., COOPER C., PELLETIER J.P., BRANCO J., BRANDI M.L., GUILLEMIN F., et al.: An algorithm recommendation for the management of knee osteoarthritis in Europe and internationally: A report from a task force of the European Society for Clinical and Economic Aspects of Osteoporosis and Osteoarthritis (ESCEO). Semin. Arthritis. Rheum., 44: 253-63, 2014.

3- ALTMAN R., LIM S., STEEN R.G. and DASA V.: Hyaluronic Acid Injections Are Associated with Delay of Total Knee Replacement Surgery in Patients with Knee Osteoarthritis: Evidence from a Large US Health Claims Database. PloS one, 10 (12): e0145776, 2015.

4- ALTMAN R.: Intra-articular sodium hyaluronate (Hyalgan®) in. J. Rheumatol., 25: 2203-12, 1998. 
5- HUSKISSON E.C. and DONNELLY S.: Hyaluronic acid in the treatment of osteoarthritis of the knee. Rheumatology, 38 (7): 602-7, 1999.

6- MAHEU E., RANNOU F. and REGINSTER J.Y.: (December). Efficacy and safety of hyaluronic acid in the management of osteoarthritis: Evidence from real-life setting trials and surveys. In Seminars in Arthritis and Rheumatism. W.B. Saunders, 2015.

7- ROOS E.M., HERZOG W., BLOCK J.A. and BENNELL K.L.: Muscle weakness, afferent sensory dysfunction and exercise in knee osteoarthritis. Nature Reviews Rheumatology, 7 (1): 57-63, 2011.

8- BENNELL K.L., WRIGLEY T.V., HUNT M.A., LIM B.W. and HINMAN R.S.: Update on the role of muscle in the genesis and management of knee osteoarthritis. Rheumatic Disease Clinics of North America, 39 (1): 145-76, 2013

9- AGEBERG E., NILSDOTTER A., KOSEK E. and ROOS E.M.: Effects of neuromuscular training (NEMEX-TJR) on patient-reported outcomes and physical function in severe primary hip or knee osteoarthritis: A controlled before-and-after study. B.M.C. musculoskeletal disorders, 14 (1), 2013.

10- AGEBERG E. and ROOS E.M.: Neuromuscular exercise as treatment of degenerative knee disease. Exercise and sport sciences reviews, 43 (1): 14-22, 2015.

11- SACCOMANNO M.F., CAZZATO G., FODALE M., SIRCANA G. and MILANO G.: Magnetic resonance imaging criteria for the assessment of the rotator cuff after repair: A systematic review. Knee Surgery, Sports Traumatology, Arthroscopy, 23 (2): 423-42, 2015.

12- BENNELL K.L., WRIGLEY T.V., HUNT M.A., LIM B.W. and HINMAN R.S.: Update on the role of muscle in the genesis and management of knee osteoarthritis. Rheumatic Disease Clinics of North America, 39 (1): 145-76, 2013.
13- KAHL C. and CLELAND J.A.: Visual analogue scale, numeric pain rating scale and the McGill Pain Questionnaire: An overview of psychometric properties. Physical Therapy Reviews, 10 (2): 123-8, 2005.

14- AGEBERG E., LINK A. and ROOS E.M.: Feasibility of neuromuscular training in patients with severe hip or knee OA: The individualized goal-based NEMEX-TJR training program. B.M.C. musculoskeletal disorders, 11 (1): 126 , 2010.

15- DIRACOGLU D., AYDIN R., BASKENT A. and CELIK A.: Effects of kinesthesia and balance exercises in knee osteoarthritis. JCR: Journal of Clinical Rheumatology, 11 (6): 303-10, 2005

16- KNOOP J., STEULTJENS M.P.M., VAN DER LEEDEN M., VAN DER ESCH M., THORSTENSSON C.A., ROORDA L.D. and DEKKER J.: Proprioception in knee osteoarthritis: A narrative review. Osteoarthritis and Cartilage, 19 (4): 381-8, 2011.

17- BUTLER A.A., LORD S.R., ROGERS M.W. and FITZPATRICK R.C.: Muscle weakness impairs the proprioceptive control of human standing. Brain Res., 1242: 244$51,2008$.

18- ELGENDY M., AMIN F., BARAKA H. and KHALED O.: Influence of Proprioceptive Training on Knee Function in Patients with Knee Osteoarthritis. Bull. Fac. Ph. Th. Cairo Univ., 10 (2), 2005.

19- KHALAJ N., OSMAN N.A.A., MOKHTAR A.H., MEHDIKHANI M. and ABAS W.A.B.W.: Balance and risk of fall in individuals with bilateral mild and moderate knee osteoarthritis. PloS one, 9 (3): e92270, 2014.

20- LIN D.H., LIN C.H.J., LIN Y.F. and JAN M.H.: Efficacy of 2 non-weight-bearing interventions, proprioception training versus strength training, for patients with knee osteoarthritis: A randomized clinical trial. Journal of orthopaedic \& sports physical therapy, 39 (6): 450-7, 2009. 


\section{تآثير التمارين العضلية العصبية على الإلتهاب العظمى المفصلى للركبه بعد حقن حمض العمي ملي الولهاب الوريورونيك}

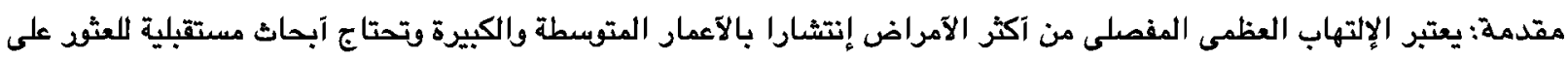

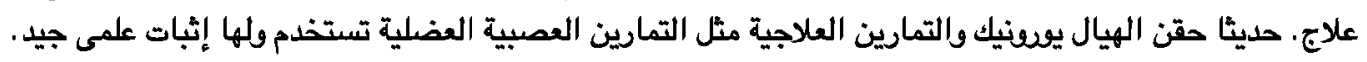

الهدف: لإكتشاف تآثير التمارين العصبية العضلية على الصركة الوظيفية للركبة المصابة بالإلتهاب العظمى المفصلى بعد حقن حمض الهياليوشونيك داخل المفصل.

آجريت هذه الدراسة على ثلاثين مريضا يعانفن من إلتهاب العظمى المفصلى للركبة وكان متوسط العمر من آربعين إلى ستين سنة تم

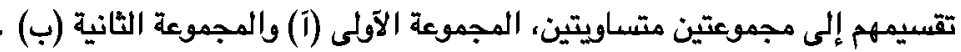

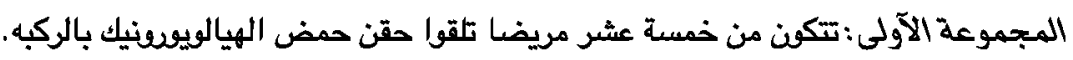

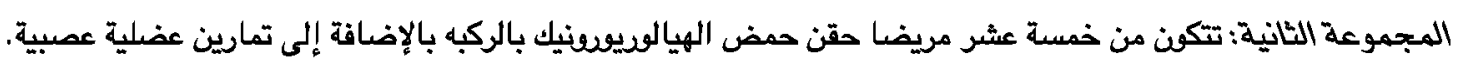
طريقة القياس: تم تقييم الآداء الوظيفى عن طريق إختبار (توقيت النهوض والحركة). آظهرت النتائج وجود تحسن في المجموعتين الآولى والثانية، وبالآخص الثانية حيث آن إضافة التمارين العصبية العضلية آوجدت نتائج آفضل من حقن الهيالويوسنيك بمفرده.

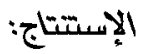
- كلا من العلاج بتطبيق حقن حمض الهيالويودنيك للركبه المصابه بإلتهاب العظمى المفصلى آى إضافة التمارين الصضلية العصبية الحقن يعطى نتائج ملحوظة. - تطبيق حقن حمض الهيالويوسنيك مع إضافة التمارين العضلية العصبية يعطى نتائج آعلى من الحقن بصوره منفرده. 


\section{APPENDIX I \\ $+4+f+f+f+f$}

\section{Neuromuscular exercises}

Exercise (1): Forwards/backwards Fig. (1):

Level (1): Sliding forwards/backwards:

Patient was asked to slide the non-arthritic leg backwards and forwards while bending and straightening the arthritic leg. Arthritic leg is nearly straight when feet are together and bent when feet are apart (aims for positioning knee over foot). The Repetitions were 3 sets of 10 with break of 30-60 seconds between sets.

Level (2): Sliding with elastic band:

The patient was asked to choose elastic band colour appropriate for the participant's ability to achieve a knee over foot position. Attach the band to unaffected and the arthritis leg. The repetitions were 3 sets of 10 with break of 30-60 seconds between sets.

Level (3): Stepping forwards/backwards (aims for positioning knee over foot):

The Repetitions were 3 sets of 10 with break of 3060 seconds between sets.

\section{Level (4): Stepping with elastic band:}

The patient was asked to choose elastic band colour appropriate for the participant's ability to achieve a knee over foot position. Attach the band to unaffected and the arthritis leg. The repetitions were 3 sets of 10 with break of 30-60 seconds between sets.

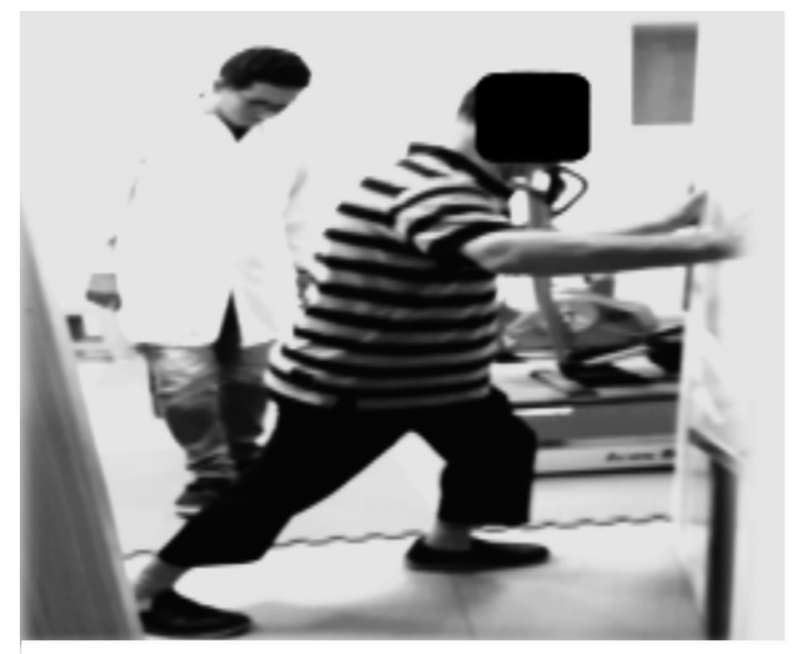

Exercise (1): Level 1

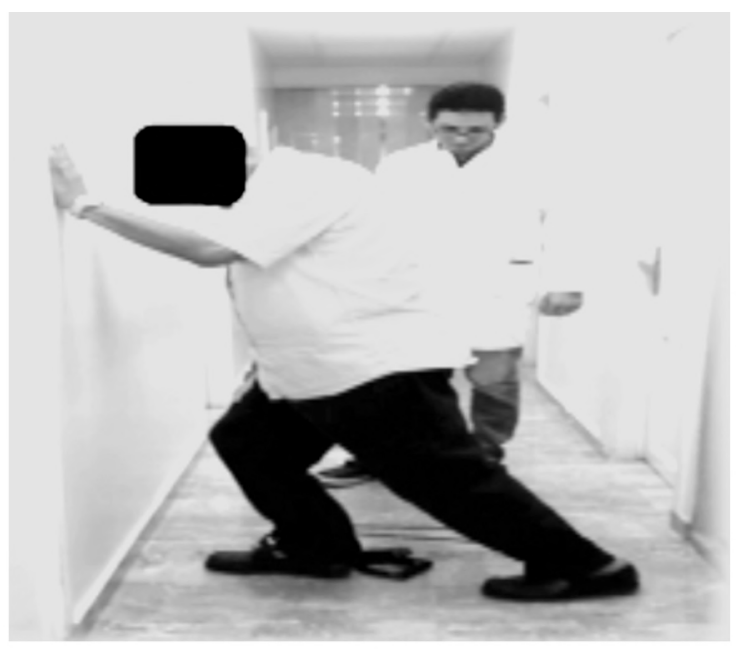

Exercise (1): Level 2

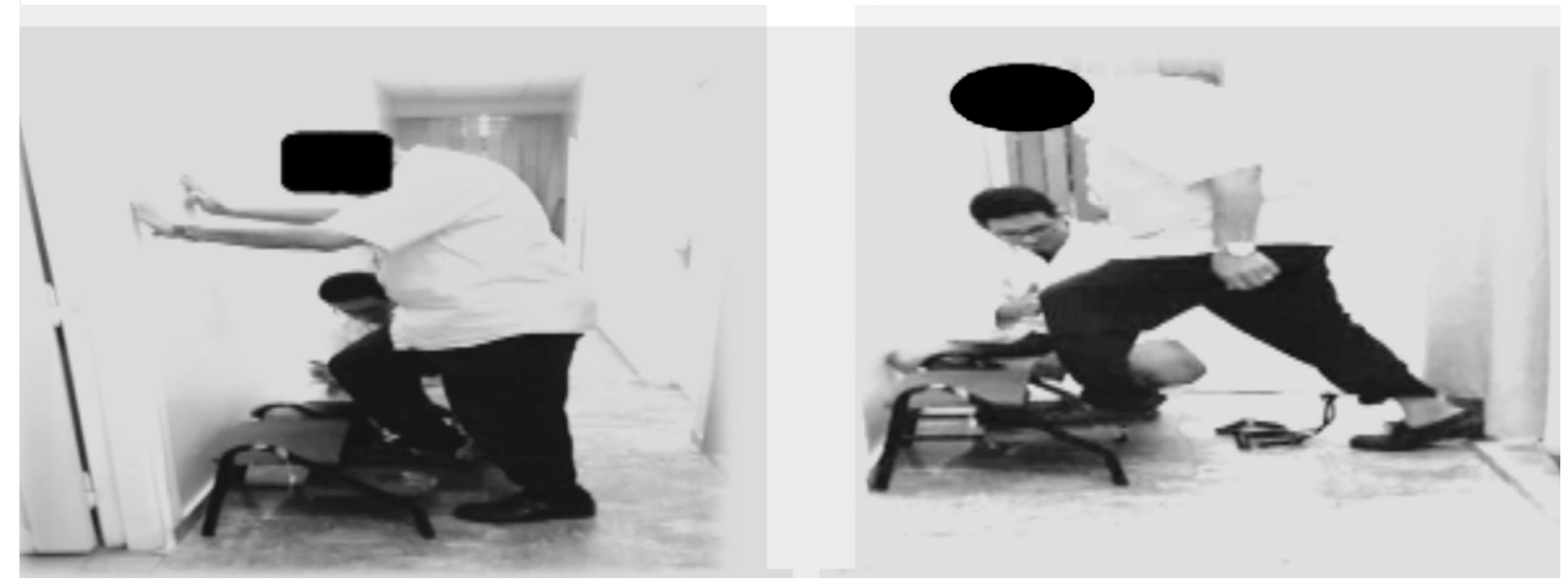

Exercise (1): Level 3

Exercise (1): Level 4

Fig. (1): Neuromuscular exercises 1 (Level 1) forward slide, (Level 2) forward slide with sling, (Level 3) step forward, (Level 4) step forward with sling. 
Exercise (2): Sideways exercise Fig. (2):

Level (1): Sliding sideways, out and in:

The patient was asked to slide the non-arthritis leg sideways while bending and straightening the arthritic leg. Arthritic leg is nearly straight when feet are together and bent when feet are a part (aims for positioning knee over foot), if patient wasn't able to stabilize himself, his hands was used for extra support. The repetitions were 3 sets of 10 with break of 30-60 seconds between sets.

\section{Level (2): Patients were asked to slide with elastic band} achieve a knee over foot position:

(Attach the band to a table leg on the arthritis leg

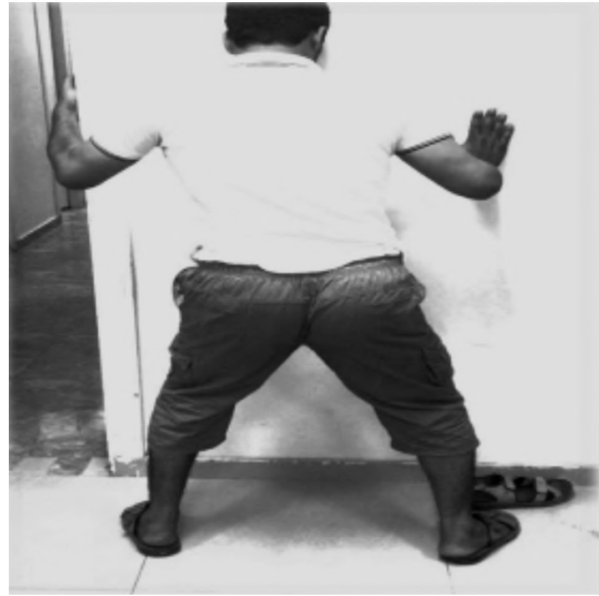

Exercise (2): Level 1 side). The repetitions were 3 sets of 10 with break of 30-60 seconds between sets.

\section{Level (3): Patients were asked to slide with elastic band} and soft surface:

(As above while standing on a pillow or cushion). The repetitions were 3 sets of 10 with break of 30-60 seconds between sets.

Level (4): Patients were asked to slide with elastic band, soft surface and eyes closed:

The repetitions were 3 sets of 10 with break of 3060 seconds between sets.

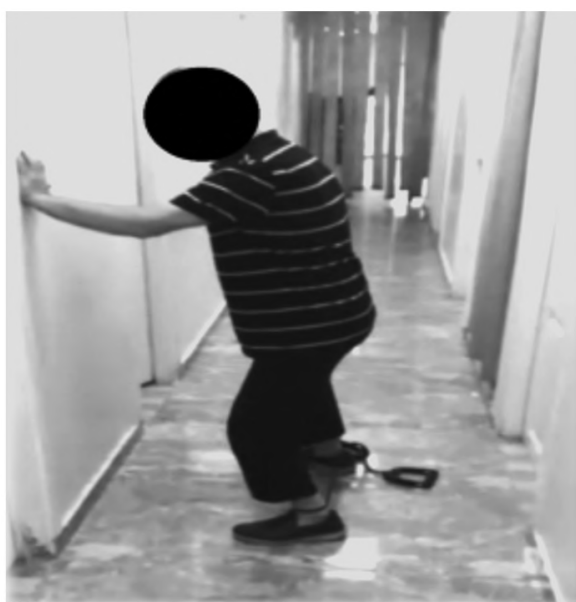

Exercise (2): Level 2

Fig. (2): Neuromuscular exercises 2 (Level 1) sideway slide, (Level 2) sideway slide with sling.

Exercise (3): Hip muscle strengthening Fig. (3):

Level (1): Wall push:

The patient was asked to stand sideways to a wall with non-arthritis leg closest to pillow against the wall. Slightly bend arthritic knee $\left(15-20^{\circ}\right)$. Push leg into the wall and hold. The repetitions were 20 second holds with short break between efforts. Two sets of 5 with break of 30-60 seconds between sets.

Level (2): Wall pushes with knee bending:

Slowly bend and straighten arthritis knee while maintaining the push. The repetitions were short break between efforts. Two sets of 5 with break of 30-60 seconds between sets.

Level (3): Crab walking with appropriate elastic band.

\section{Level (4): Using higher resistance band than in Level} (3):

The repetitions were Total of 30 steps in each direction. With elastic band around ankles, step sideways in both directions maintain slight knee bend throughout. 


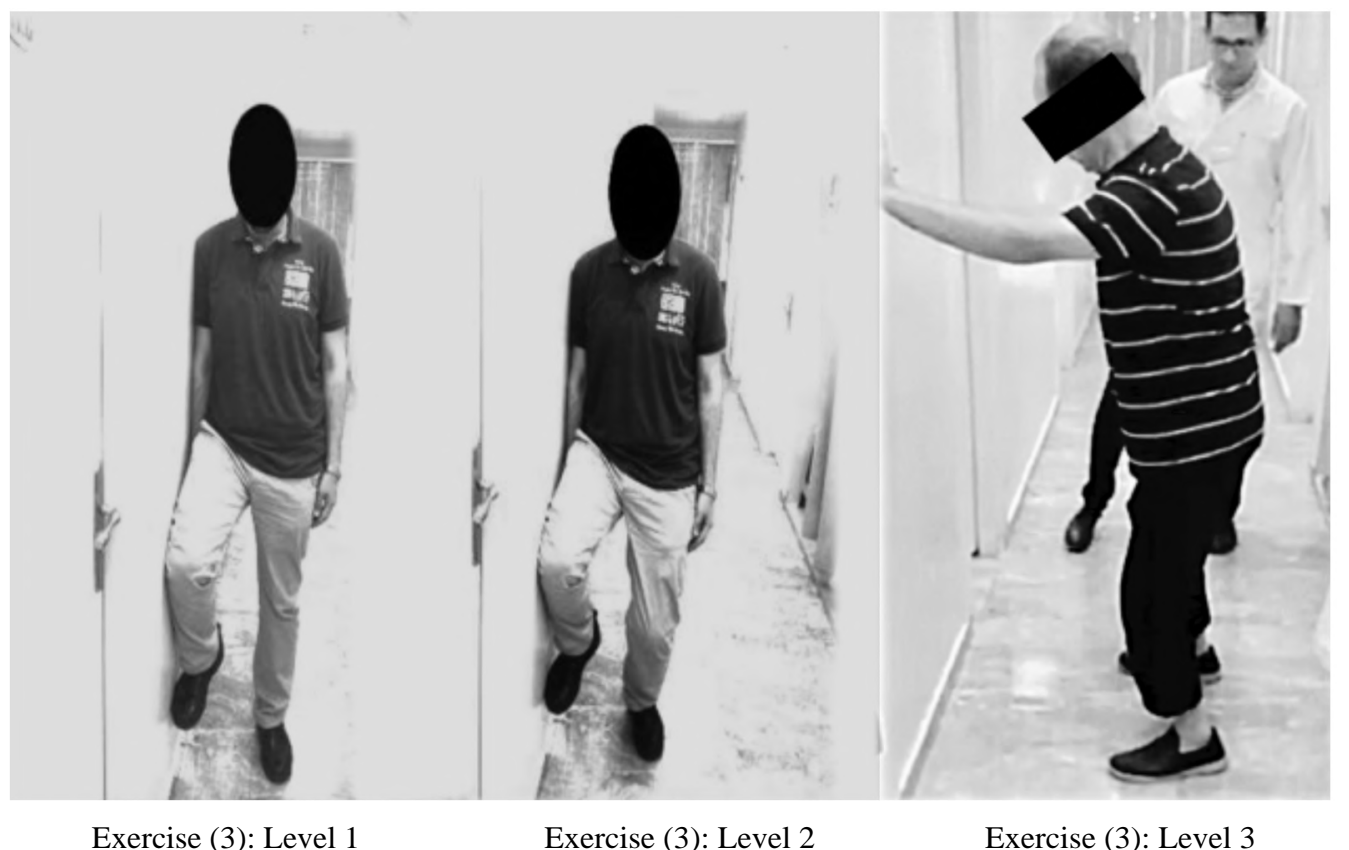

Fig. (3): Neuromuscular exercises 3 (Level 1) wall push, (Level 2) wall push with knee bending, (Level 3) crab walk with elastic band.

Exercise (4): Knee muscle strengthening Fig. (4): Level (1): Wall squats:

The patient was asked to stand with back to a wall, feet were apart and one foot length away from the wall. Slide slowly down the wall to about $30^{\circ}$ bend, then slide up again (aims for positioning knee over foot). The repetitions were 3 sets of 10 with break of 30-60 seconds between sets.

\section{Level (2): The patient was asked for wall squats with more weight on arthritis leg:}

(Shift weight more over arthritis leg). The repetitions were 3 sets of 10 with break of 30-60 seconds between sets.
Level (3): The patient was asked for chair stands:

The patient was asked to start sitting on a standard height (eg. kitchen) chair. Reach hands out in front; if needed therapist hand was guide trunk or patient hands. Patient asked to stand up and sit down slowly (aim at positioning knee over foot). The repetitions were 3 sets of 10 with break of 30-60 seconds between sets.

Level (4): The patient was asked for chair stands with adequate resistance against shoulders:

The repetitions were 3 sets of 10 with break of 30 60 seconds between sets.

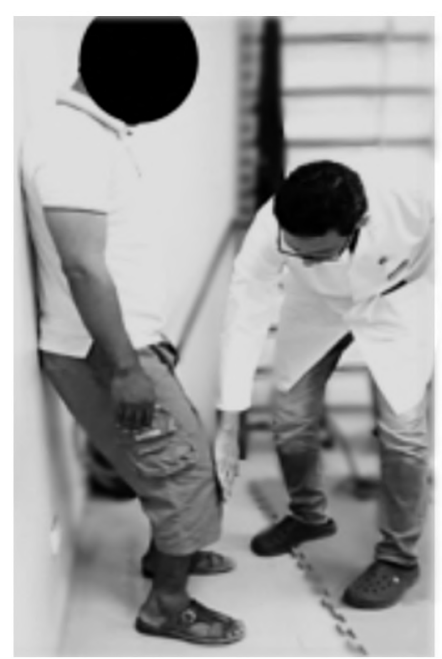

Exercise (4): Level 1
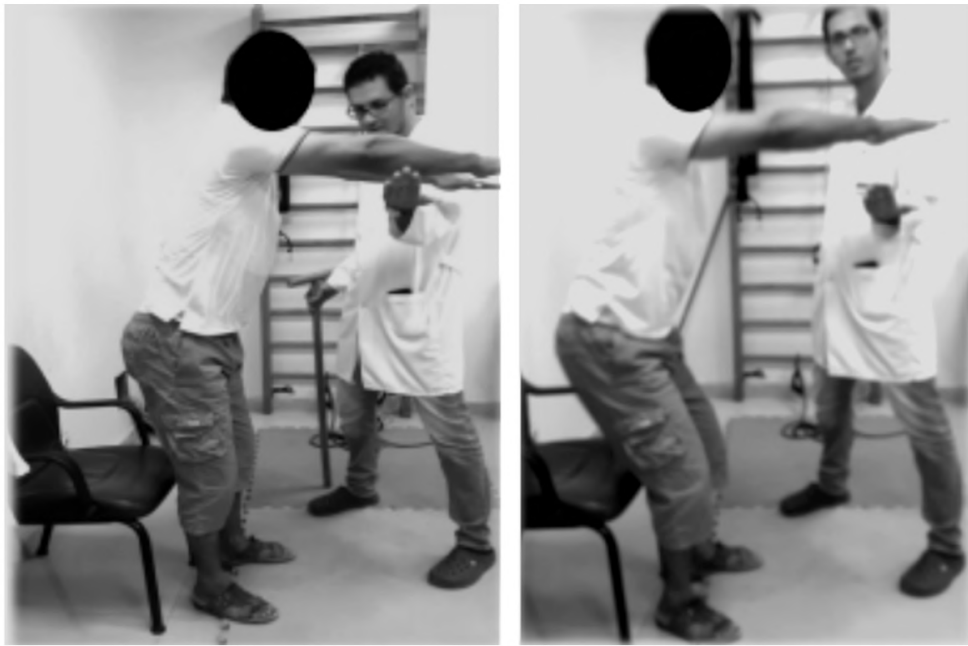

Exercise (4): Level 2

Fig. (4): Neuromuscular exercises 4 (Level 1) wall squats, (Level 2) chair stands. 


\section{Level (1): Step-ups:}

The patient was asked to place arthritic leg onto a step, slowly step up onto the step and to make nonarthritis foot to touch the step then step back down slowly to the start position (aims for positioning knee over foot). The Repetitions were 3 sets of 10 with break of 30-60 seconds between sets.

Level (2): Patients were asked to step-ups with higher step (aim at positioning knee over foot):

The repetitions were 3 sets of 10 with break of 3060 seconds between sets.

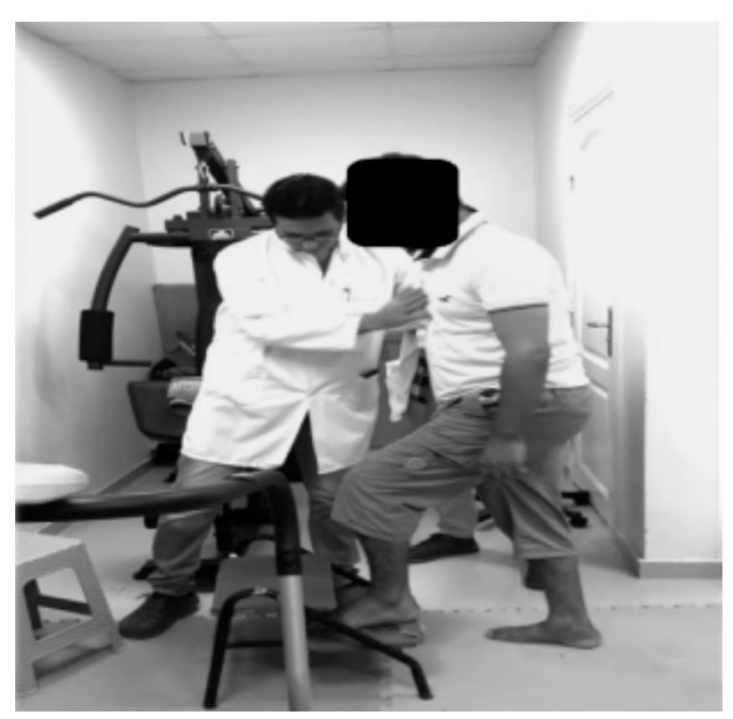

Exercise (5): Level 1

\section{Level (3): Patient was asked to touch downs:}

Patient was asked to start standing on the step and to make non-arthritic foot touch the floor in front and then back the step (aim at positioning knee over foot). The repetitions were 3 sets of 10 with break of 30-60 seconds between sets.

Level (4): Touch downs with higher step (aim at positioning knee over foot):

The repetitions were 3 sets of 10 with break of 30 60 seconds between sets.

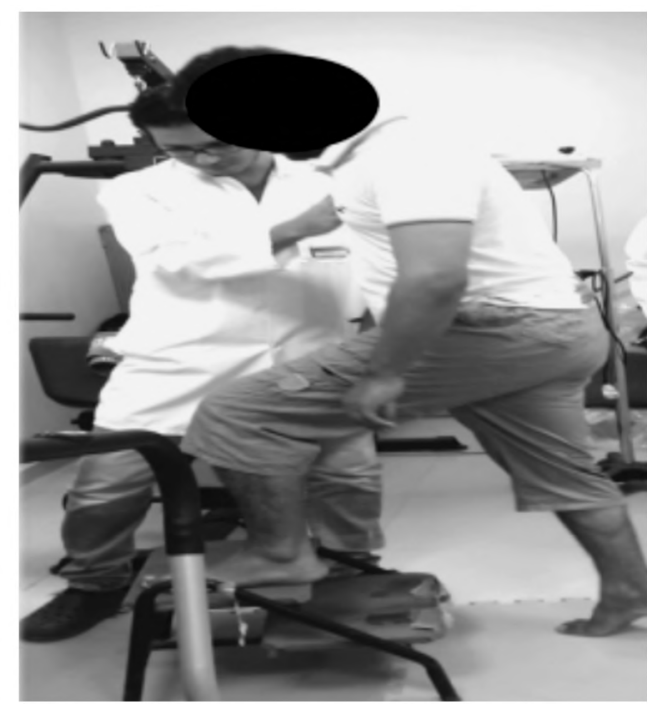

Exercise (5): Level 2

Fig. (5): Neuromuscular exercises 5 (Level 1) step-up, (Level 2) step-up with higher step. 